\title{
Psychiatric and behavioral problems and well-being in gerontopsychiatric nursing home residents
}

Citation for published version (APA):

van der Wolf, E., van Hooren, S. A. H., Waterink, W., \& Lechner, L. (2021). Psychiatric and behavioral problems and well-being in gerontopsychiatric nursing home residents. Aging \& Mental Health, 25(2), 277-285.

https://doi.org/10.1080/13607863.2019.1695738

DOI:

10.1080/13607863.2019.1695738

Document status and date:

Published: 01/02/2021

Document Version:

Publisher's PDF, also known as Version of record

Document license:

Taverne

Please check the document version of this publication:

- A submitted manuscript is the version of the article upon submission and before peer-review. There can be important differences between the submitted version and the official published version of record. People interested in the research are advised to contact the author for the final version of the publication, or visit the DOI to the publisher's website.

- The final author version and the galley proof are versions of the publication after peer review.

- The final published version features the final layout of the paper including the volume, issue and page numbers.

Link to publication

\section{General rights}

Copyright and moral rights for the publications made accessible in the public portal are retained by the authors and/or other copyright owners and it is a condition of accessing publications that users recognise and abide by the legal requirements associated with these rights.

- Users may download and print one copy of any publication from the public portal for the purpose of private study or research.

- You may not further distribute the material or use it for any profit-making activity or commercial gain

- You may freely distribute the URL identifying the publication in the public portal.

If the publication is distributed under the terms of Article 25fa of the Dutch Copyright Act, indicated by the "Taverne" license above, please follow below link for the End User Agreement:

https://www.ou.nl/taverne-agreement

Take down policy

If you believe that this document breaches copyright please contact us at:

pure-support@ou.nl

providing details and we will investigate your claim.

Downloaded from https://research.ou.nl/ on date: 26 Apr. 2023 


\title{
Psychiatric and behavioral problems and well-being in gerontopsychiatric nursing home residents
}

\author{
Elja van der Wolf ${ }^{a, b}$ (D), Susan A. H. van Hooren ${ }^{b, c, d}$, Wim Waterink ${ }^{b}$ and Lilian Lechner ${ }^{b}$ (ID)

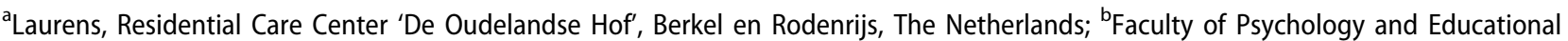 \\ Sciences, Open University, Heerlen, The Netherlands; ${ }^{C}$ Faculty of Healthcare, Zuyd University of Applied Sciences, Heerlen, The \\ Netherlands; ${ }^{d}$ Research Centre for the Arts Therapies, KenVaK, Heerlen, The Netherlands
}

\begin{abstract}
Objectives: Gerontopsychiatric nursing home residents are residents with a chronic mental condition (not dementia), in combination with one or more physical disorders. Psychiatric and behavioral problems are common within this population. The objective of this study is to examine these behaviors and their relationship to the level of both observed and self-rated well-being in the gerontopsychiatric population.

Method: Both gerontopsychiatric residents, and their primary formal caregiver in several nursing homes in The Netherlands were asked to participate in a structured interview concerning psychiatric and behavioral problems and resident well-being. Psychiatric and behavioral problems were measured with the Neuropsychiatric Inventory Questionnaire (NPI-Q) and the Cohen Mansfield Agitation Index (CMAI). Well-being was measured through the self-rated Laurens Well-being Inventory for Gerontopsychiatry (LWIG), and the observer rated Laurens Well-being Observations for Gerontopsychiatry (LWOG).

Results: A total of 126 residents participated in the study with ages varying from 42 to 90 . Different types of chronic mental disorders such as schizophrenia spectrum disorder, bipolar disorders and personality disorders were prevalent in the population. Most psychiatric and behavioral problems are associated with lower observed and self-rated well-being. For irritability and affective problem behaviors the relationship with well-being was the most evident

Conclusion: In daily care practice the relationship between well-being and psychiatric and behavioral problems should be taken into account in care planning and treatment. To further explore the direction and details of this relationship, more research is needed.
\end{abstract}

\section{ARTICLE HISTORY}

Received 21 February 2019

Accepted 15 November 2019

\section{KEYWORDS}

Well-being; aging; psychiatry; long term-care; behavioral problems

\section{Introduction}

The gerontopsychiatric population consists of older people with both a chronic mental disorder (other than dementia), and one or more physical disorders. Within this population long term care is often needed and provided. On average, one in six to twelve long-term care residents is part of the gerontopsychiatric population. In the Netherlands for example, this was found to be just over eight percent of the nursing home population (Stuurgroep Gerontopsychiatrie, 2012), and in the United States this population accounts for about 18 percent of the long term care population (Fullerton, McGuire, Feng, Mor, \& Grabowski, 2009).

The gerontopsychiatric population differs from other nursing home residents in several respects. Gerontopsychiatric residents are often younger, unmarried, a larger proportion is male (Van den Brink, Gerritsen, Voshaar, \& Koopmans, 2013) and there is a higher incidence of psychiatric or behavioral problems than in patients with dementia (Collet, De Vugt, Verhey, Engelen, \& Schols, 2016; Van den Brink, Gerritsen, De Valk, Voshaar, \& Koopmans, 2017; Van den Brink et al., 2013).

Psychiatric and behavioral problems in the gerontopsychiatric population can present in many forms such as irritability, delusions, apathy, constant requests for attention and verbal aggression (Van den Brink et al., 2017).
These behaviors are a major focus of attention in nursing homes in terms of both pharmacological and nonpharmacological treatment (Abraha et al., 2017; Chiu, Bero, Hessol, Lexchin, \& Harrington, 2015). They lead to an increase in costs and caregiver hours (Herrmann et al., 2006; Neubauer, Holle, Menn, Grossfeld-Schmitz, \& Graesel, 2008) and may negatively impact on the health and job satisfaction of nurses (Evers, Tomic, \& Brouwers, 2001; Testad, Mikkelsen, Ballard, \& Aarsland, 2009).

As well as the negative effects on the care-workers, behavioral problems have often been associated with a decreased level of well-being of nursing home residents (Samus et al., 2005; Ven-Vakhteeva, Bor, Wetzels, Koopmans, \& Zuidema, 2013; Winzelberg, Williams, Preisser, Zimmerman, \& Sloane, 2005). Providing a pleasant living environment, at the highest possible level of well-being is one of the main objectives in nursing home care (Hamers, 2011). Increasing our knowledge about the relationship between problem behavior and well-being is a crucial first step in improving our interpretation and treatment of problem behavior, and in so doing to strive for the highest possible well-being for the target population.

In this study the relationship between well-being and the incidence of behavioral problems among gerontopsychiatric nursing home residents is examined. Well-being 
is a broad concept, and the definition has been the focus of much discussion in the literature (Ryan \& Deci, 2001). In this article, the following definition of well-being will be used: 'a multidimensional concept that concerns the individuals' cognitive and emotional evaluations of their lives' (Van der Wolf, Van Hooren, Waterink, \& Lechner, 2018).

As shown in a recent review, no research has been conducted on the relationship between well-being and behavioral problems in the gerontopsychiatric nursing home population (Van der Wolf, Van Hooren, Waterink, \& Lechner, 2017). Research has however been conducted in the population of nursing home residents with dementia. Results from this population are not entirely applicable to the gerontopsychiatric population as the prominent cognitive problems have a large impact on the behavior of residents with dementia. The results can however give some insight in the possible relationship between well-being and behavioral problems, considering several similarities between the populations that are relevant to both (problem) behavior and well-being, such as the living environment with others that are not family, dependency on care and (relatively) older age. In the population with dementia, a negative relationship between behavioral problems and well-being has been found, both in cross-sectional (Samus et al., 2005; Vogel, Mortensen, Hasselbalch, Andersen, \& Waldemar, 2006; Winzelberg et al., 2005; Zimmerman et al., 2005), in longitudinal (Ven-Vakhteeva et al., 2013) and in a small $(n=31)$ double blind randomized control study on the effect of psychotropic medication on behavioral symptoms and quality of life (Kristin Martin-Cook, Hynan, RiceKoch, Svetlik, \& Weiner, 2005). These studies show that an occurrence of behavioral problems is related to diminished quality of life.

A correlation between well-being and behavioral problems was, however only found when well-being was rated with a caregiver-rated instrument. Self-rated well-being was not shown to be related to behavioral problems (Vogel et al., 2006; Yap et al., 2008; Zimmerman et al., 2005). Also when well-being was measured through 'detailed observations of the residents behavior' during a $5 \mathrm{~h}$-period, no relation with behavioral problems was found (Ballard et al., 2001).

There are several possible explanations for the difference between the relationship of behavioral problems when using self-rated as opposed to caregiver-rated wellbeing measurement instruments. Primarily this difference could be indicative of a reduced ability of people with dementia to assess their own well-being due to cognitive impairment and denial of problems (Clare, 2002; Tatsumi et al., 2009). Another possible explanation is that behavioral problems might, justly or unjustly, be interpreted by nurses as a sign of reduced well-being, influencing the caregiver-rated well-being score. Finally, an underlying factor, such as caregiver burden or feelings of depression in the caregiver, might influence the results on both the observer-rated well-being and the problem-behavior instruments, as both concepts are often measured by the same observer. This may cause a slightly over inflated correlation (Logsdon, Gibbons, McCurry, \& Teri, 2002; Zimmerman et al., 2005). Both observer-rated and self-rated well-being may therefore have strengths and limitations in the measurement of well-being and its correlation with psychiatric and behavioral problems.
In this study using interviews with the formal caregiver, we examined the link between self-rated well-being and observed well-being with the occurrence and frequency of behavioral problems within the gerontopsychiatric population (through interviews with the formal caregiver). We hypothesize that behavioral problems are associated with lower observed well-being. As cognitive impairment plays a smaller role in the gerontopsychiatric population than in the population described above, we hypothesize there will be a (weak) relationship between behavioral problems and self-rated well-being.

\section{Method}

\section{Design and subjects}

Subjects were all residents of a gerontopsychiatric ward, in one of four selected nursing homes in The Netherlands. One of these facilities was a general nursing home with several gerontopsychiatric wards, the other three were specialized nursing homes for the gerontopsychiatric population. Data were collected in the period from April 2014 to April 2015 in a cross sectional study design. Inclusion criteria for the participants were: living at least one month in the institution, receiving long term care (no revalidation or temporary care) and having one or more DSM IV diagnoses. Exclusion criteria were dementia (other than Korsakov's dementia) as a primary diagnosis or inability to participate in the interview due to cognitive or physical limitations. This was assessed by the first-responsible nurse (i.e. the nurse that, within the team of nurses, bears primary responsibility for the care of this resident) or it was established by the researcher during the interview, if it appeared that the resident was unable to understand or answer the questions. There were no age-restrictions.

\section{Procedure}

Both residents and their first-responsible nurse were interviewed by the first author or by one of three trained research assistants for data collection. A letter describing the content and purpose of the study, was sent to the residents and their family member or legal representative, one or two weeks in advance. Information on the content and purpose of the study was provided again before the interview, and informed consent was given by all participants. Informed consent was also sought from the legal representative of the resident if the first-responsible nurse deemed it necessary. This procedure was approved by the research ethics committee (cETO) of the Open University of the Netherlands (ref no: U2013/03517/CBO).

\section{Measures}

\section{Well-being}

For the measurement of well-being, two instruments were used that were recently developed specifically for the gerontopsychiatric population. One instrument measured selfrated well-being: the Laurens Well-being Inventory in Geronto-psychiatry (LWIG) (Van der Wolf et al., 2018), and one instrument measured well-being by proxy: the Laurens Well-being Observations for Gerontopsychiatry (LWOG). 
The LWIG is a self-rated 30 -item well-being measure. It contains six subscales within three dimensions: physical well-being, social well-being and psychological well-being. This study focused on the three dimensions of well-being and not on the six subscales for purposes of conciseness. A 4-point answer scale is used for all items. The range of the total scale is 30 to 120 , with a higher score indicating a higher level of well-being. Reliability of the LWIG is sufficient, McDonalds Omega's of the subscales vary from .68 to .84. Validity is adequate as the scale correlates sufficiently with another self-rated well-being measure, i.e. $r>.40(p<.01)$ with Cantril's ladder (Cantril, 1965; Van der Wolf et al., 2018). Although self-rated and observer rated well-being is generally only weakly correlated, the LWIG subscales were significantly related to most of the observer-rated Qualidem subscales (Ettema, Dröes, De Lange, Mellenbergh, \& Ribbe, 2007; Van der Wolf et al., 2018)

The LWOG is a 12-item observer-rated well-being instrument. It consists of two subscales, a social, positive subscale with items like 'there are nurses with whom the resident has a good relationship' and a psychological negative subscale with items like 'was anxious or tense'. The instrument uses a 4-point answer scale, and the range of the total scale is 12 to 48 , with a higher score indicating a higher level of well-being. A sufficiently high reliability of the LWOG was found with McDonalds Omega's of the total scale and subscales varying from .80 to .82 . Validity of the LWOG is demonstrated, with adequate correlations, $r$ varying from .39 to $.69(p<.01)$ with the observer-rated Qualidem subscales (Ettema et al., 2007), and with the selfrated well-being measure, Cantril's Ladder $(r=.23, p<.01)$. The relation with the LWIG subscales was also examined by Van der Wolf et al. . It was found that all subscales of both instruments were significantly related, with stronger relations between the psychological negative LWOG subscale and the physical $(r=.42, p<.01)$, the psychological $(r=.37$, $p<.01)$ and the social $(r=.23, p<.01)$ LWIG subscales. The relations between the social positive LWOG subscale and the LWIG subscales were lower, but also significant: $r=.28$, $p<.01$ for the physical scale, $r=.23, p<.01$ for the psychological subscale and $r=.19, p<.01$ for the social subscale.

\section{Behavioral problems}

Agitation and aggression was measured using the Cohen Mansfield Agitation Inventory, Dutch version (CMAI-D) (Cohen-Mansfield, Marx, \& Rosenthal, 1989). This is a 29item instrument, measuring the frequency of agitated behavior, through the observations of the primary formal caregiver. A total agitation score and three subscales (i.e. aggressive behavior, physical non-aggressive behavior and verbal agitation) are computed (Zuidema, De Jonghe, Verhey, \& Koopmans, 2007a). The items are rated on a 7 -point scale, ranging from never (1) to several times an hour (7). The range of this scale is 29 to 203, with higher scores indicating more frequent occurrence of agitated or aggressive behavior. Good validity and reliability has been reported (Cohen-Mansfield \& Libin, 2004).

Behavioral problems can also occur in the form of neuropsychiatric symptoms like apathy, delusions and hallucinations. These symptoms were measured with the Neuropsychiatric Inventory Questionnaire (NPI-Q), an abbreviated version of the NPI (Cummings et al., 1994; Kaufer et al., 2000). The NPI-Q is a caregiver-rated instrument, and examines 12 neuropsychiatric symptoms. Items consist of a screening question, with a yes/no answer scale, followed by a severity assessment using a 3-point answer scale varying from mild (1), moderate (2) to severe (3). This scale ranged from 0 (no neuropsychiatric behaviors) to 36 (severe neuropsychiatric behaviors). Reliability and validity of the NPI-Q have been established (De Jonghe, Kat, Kalisvaart, \& Boelaarts, 2003; Kaufer et al., 2000). Subscales in different compositions have been established for populations with dementia (Canevelli et al., 2013). Because in the current study a different target group was examined, and to be able to include groupings of related behaviors in the model, the factor structure was determined in the data itself, using principal components analysis.

As the components were not highly correlated $(r \leq .22)$, orthogonal rotation was chosen. Based on Kaiser's criterion, a clear and understandable 4- component solution was found, explaining $55.6 \%$ of the variance. The first component consisted of irritability, agitation and anxiety, three behavioral symptoms that are all stress- or tension related. This component was named the 'tension-component. The second component contained disinhibition, euphoria and aberrant motor behavior, three symptoms that are related to disturbed inhibition. This component was named the 'disinhibition-component. The third component consisted of nighttime behavior, depression, apathy and appetite, all depression related symptoms. This component was called the 'depression-component'. The last component consisted of delusions and hallucinations, and was named the 'psychosis-component'.

\section{Potential confounders}

The correlation between behavioral problems and level of well-being can be confounded by several patient characteristics. To be able to control for confounders, data on several characteristics were collected. Level of functioning was evaluated by the physician, using the Global Assessment of Functioning Scale (GAF) (Endicott, Spitzer, Fleiss, \& Cohen, 1976). ADL dependency was measured through interviews with the first-responsible nurse, using the Barthel Index (Mahoney \& Barthel, 1965). This is a 10-item index with items on dependency concerning tasks like bathing, feeding and toilet use. It was found to be reliable in different ways of administration (Intraclass-correlation $=.89$ ) and on testing by different observers (Intraclass correlation .95 to .97) (Sainsbury, Seebass, Bansal, \& Young, 2005).

Electronic client dossiers (ECD) were consulted to collect diagnostic data and some demographic data (i.e. age and duration of stay in current residence). Diagnoses were checked and confirmed by the appointed elderly care physician. Other demographic data on educational level (low education: 'Lower than elementary school', 'primary school completed' and 'primary school and two years follow up education', medium education: 'vocational education' and 'middle-level applied education', and high education: 'higher education' and 'academic education') and marital status ('married or living together', 'single', 'divorced', 'widowed') was requested from the residents themselves. 


\section{Data analysis}

SPSS version 22 was used for all statistical analyses. Assumptions of linearity were visually inspected using scatterplots. All correlations among the independent variables were .49 or lower, suggesting that multicollinearity is not a problem (Tabachnick \& Fidell, 2014). Durbin-Watson scores (for the LWIG) varied from 1.71 to 2.01 , suggesting independent errors (Field, 2009). Using scatterplots, the relationship between the dependent and independent variables were visually checked. No non-linear relationships were observed. No outliers were found (IQR $>3$ ).

Due to the fact that some of the collected data was part of a pilot-study in the development of two well-being scales (LWIG and LWOG), the data of 28 of the participants are missing on some specific items. This is the case for one LWIG item ('I am sometimes being bullied') and for two LWOG items ('responded positively to jokes or humor' and 'tried to make the best of the current situation'). As 28 participants is a substantial percentage of the total group of participants, exclusion of these data would largely impact the power of the results. Therefore imputation of the missing data was considered. Participants for whom the data were missing were randomly selected, and were consequently not expected to differ as a group from the other 98 participants. Using independent samples t-tests the well-being scores of the 28 participants with missing data were compared to the 98 participants that had no missing data. No significant differences were found, confirming this expectation. Furthermore, results on the specific items with missing values were visually compared to the other items in the instrument using histograms. No striking differences were found. Data were therefore imputed using expectation maximization (Gold \& Bentler, 2000). For all other variables, only data on age was missing for two participants, there were no other missing values.

Multiple linear regression was performed, with the scores of the subscales of both well-being measures as dependent variables and the different scales of the measures on problem behavior, CMAI and NPI, as independent variables.
The first step was to examine the potential relevant covariates, correlations (for continuous variables) and analysis of variance (ANOVA) (for categorical variables). Only those variables that had a significant relationship with one or both of the well-being measures were added as covariates. A series of linear multiple regressions were then performed, with the different subscales of the well-being instruments as the dependent variable. Forced entry was used as method, and the variables were included in two blocks: relevant covariates in the first block, and psychiatric and behavioral problems in the second block. Cohens $f^{2}$ was used as an effect size, defined as small $\left(f^{2} \geq .02\right)$, medium $\left(f^{2} \geq .15\right)$ and large $\left(f^{2} \geq .35\right)$ (Cohen, 1977; Soper, 2019).

\section{Results}

\section{Participant characteristics}

From the total population of 225 nursing home residents, a total of 126 residents agreed to participate in the study, a participation rate of $56 \%$. The participating population comprised of 88 women and 38 men, with ages varying from 42 to 90 (mean 66.8). Schizophrenia spectrum disorder was the most common primary diagnosis (50\%). Other disorders were depressive disorders (11.1\%), bipolar or related disorders $(11.1 \%)$, personality disorders (5.6\%), neurocognitive disorders (9.5\%) and other disorders (12.7\%). Mean GAF score was 32.3 $(S D=8.29)$, varying from 15 to 60 . Duration of stay in de the current institution varied from 2 months to 14.4 years (mean 4 years). Concerning marital status, 36.3\% were unmarried, $35.5 \%$ were divorced, $16.9 \%$ of the participants were widowed and $11.3 \%$ were married or living together. For an overview of results on dependent and independent variables, see Table 1. Since gender was found to be an important covariate with significant differences on self-rated well-being, data in the table were subdivided by gender.

Table 1. Results on well-being and behavioral measures.

\begin{tabular}{|c|c|c|c|c|}
\hline & Mean total $(S D)(N=126)$ & Mean women $(S D)(N=88)$ & Mean men $(S D)(N=38)$ & Difference gender $^{\mathrm{a}}$ \\
\hline \multicolumn{5}{|l|}{ Self-rated well-being (LWIG) } \\
\hline Total LWIG score (range 30 to 120 ) & $81.2(16.7)$ & $78.6(15.4)$ & $87.2(18.4)$ & $\mathrm{t}(124)=2.70^{* *}$ \\
\hline Physical well-being (range 6 to 24) & $16.0(4.2)$ & $15.5(3.9)$ & $17.3(4.7)$ & $\mathrm{t}(124)=2.26^{*}$ \\
\hline Psychological well-being (range 11 to 44 ) & $30.9(7.6)$ & $30.0(7.4)$ & $33.2(7.9)$ & $t(124)=2.21^{*}$ \\
\hline Social well-being (range 13 to 52 ) & $34.3(7.7)$ & $33.2(7.3)$ & $36.7(8.1)$ & $t(124)=2.40^{*}$ \\
\hline \multicolumn{5}{|l|}{ Observed well-being (LWOG) } \\
\hline Total LWOG score (range 12 to 48 ) & $35.9(6.0)$ & $35.7(6.2)$ & $36.2(5.6)$ & NS \\
\hline Social-positive subscale (range 7 to 28 ) & $21.8(3.9)$ & $21.9(3.9)$ & $21.4(3.9)$ & NS \\
\hline Psychological-negative subscale (range 5 to 20) & $14.1(3.8)$ & $13.8(3.7)$ & $14.8(4.0)$ & NS \\
\hline \multicolumn{5}{|l|}{ Neuropsychiatric symptoms (NPI-Q) } \\
\hline Total NPI-Q score (range 0 to 36 ) & $8.5(5.7)$ & $9.0(5.5)$ & $7.4(6.2)$ & NS \\
\hline Tension component (range 0 to 9 ) & $3.2(2.6)$ & $3.3(2.6)$ & $2.9(2.7)$ & NS \\
\hline Disinhibition component (range 0 to 9 ) & $1.4(1.8)$ & $1.4(2.0)$ & $1.4(1.6)$ & NS \\
\hline Depression component (range 0 to 12 ) & $2.7(2.5)$ & $3.0(2.5)$ & $2.0(2.6)$ & $t(124)=-2.15^{*}$ \\
\hline Psychosis component (range 0 to 6 ) & $1.2(1.6)$ & $1.3(1.6)$ & $1.1(1.7)$ & NS \\
\hline \multicolumn{5}{|l|}{ Agitated behavior (CMAI) } \\
\hline Total CMAI score (range 29 to 203) & $47.7(14.5)$ & $47.1(14.2)$ & $49.1(15.4)$ & NS \\
\hline Verbal aggressive behavior (range 4 to 28 ) & $11.6(6.2)$ & $11.5(5.9)$ & $11.9(7.0)$ & NS \\
\hline Physical non-aggressive behavior (range 7 to 49 ) & $11.7(5.4)$ & $11.5(5.2)$ & $12.2(5.7)$ & NS \\
\hline Physical aggressive behavior (range 8 to 56 ) & $12.3(5.0)$ & $12.2(5.2)$ & $12.4(4.3)$ & NS \\
\hline
\end{tabular}

LWIG = Laurens Well-being Inventory for Gerontopsychiatry; LWOG=Laurens Well-being Observations for Gerontopsychiatry; NPI-Q = Neuropsychiatric Inventory-Questionnaire; tension component contains irritability, agitation and anxiety, disinhibition component contains disinhibition, euphoria and aberrant motor behavior, depression component contains nighttime behavior, depression, apathy and appetite, psychosis component contains delusions and hallucinations; CMAI = Cohen Mansfield Agitation Index; Results are based on imputed data.

andependent samples t-tests were used to test for differences between women and men; ${ }^{*} p<.05 ;{ }^{*} *_{p}<.01$. 
Table 2. Hierarchical multiple regression of behavioral problems on self-rated well-being scores.

\begin{tabular}{|c|c|c|c|c|c|c|c|c|c|}
\hline & \multicolumn{3}{|c|}{ LWIG physical } & \multicolumn{3}{|c|}{ LWIG psychological } & \multicolumn{3}{|c|}{ LWIG social } \\
\hline & & $B(S E)$ & $\beta$ & & $B(S E)$ & $\beta$ & & $B(S E)$ & $\beta$ \\
\hline \multicolumn{10}{|l|}{ Block 1} \\
\hline Constant & & $2.61(.38)$ & & & $2.86(.37)$ & & & $3.24(.33)$ & \\
\hline Sex & & $-.23(.14)$ & -.15 & & $-.28(.13)$ & $-.19 *$ & & $-.27(.12)$ & $-.21^{*}$ \\
\hline Barthel score & & $.03(.01)$ & $.21^{*}$ & & $.02(.01)$ & $.20^{*}$ & & $-.00(.01)$ & -.03 \\
\hline GAF & & $.01(.01)$ & .05 & & $.00(.01)$ & .04 & & $.01(.01)$ & .08 \\
\hline Level of education & & $.00(.04)$ & .01 & & $.01(.04)$ & .02 & & $-.06(.03)$ & -.17 \\
\hline$R^{2}$ & $.09 *$ & & & $.08^{*}$ & & & $.08^{*}$ & & \\
\hline \multicolumn{10}{|l|}{ Block 2} \\
\hline Constant & & $2.83(.44)$ & & & $2.59(.44)$ & & & $3.40(.39)$ & \\
\hline Sex & & $-.15(.14)$ & -.10 & & $-.21(.13)$ & -.14 & & $-.22(.12)$ & -.17 \\
\hline Barthel score & & $.01(.01)$ & .11 & & $.02(.01)$ & .16 & & $-.01(.01)$ & -.12 \\
\hline GAF & & $.01(.01)$ & .09 & & $.01(.01)$ & .10 & & $.01(.01)$ & .11 \\
\hline Level of education & & $.00(.04)$ & .01 & & $.01(.04)$ & .03 & & $-.07(.03)$ & $-.18^{*}$ \\
\hline Tension component & & $-.07(.09)$ & -.08 & & $-.18(.09)$ & $-.23^{*}$ & & $-.09(.08)$ & -.14 \\
\hline Disinhibition component & & $.19(.11)$ & .17 & & $.26(11)$ & $.24^{*}$ & & $.11(.10)$ & .11 \\
\hline Depression component & & $-.31(.11)$ & $-.28^{* *}$ & & $-.15(.11)$ & -.13 & & $-.23(.10)$ & $-.24 *$ \\
\hline Psychosis component & & $-.02(.08)$ & -.03 & & $-.02(.08)$ & -.03 & & $.05(.07)$ & .06 \\
\hline CMAI verbally aggressive & & $-.02(.05)$ & -.05 & & $-.02(.05)$ & -.05 & & $-.03(.04)$ & -.07 \\
\hline CMAI physical not-aggressive & & $-.00(.09)$ & -.00 & & $.11(09)$ & .13 & & $.00(.08)$ & .01 \\
\hline CMAI physical aggressive & & $-.01(.12)$ & -.01 & & $.06(.12)$ & .05 & & $.03(.10)$ & .03 \\
\hline$\Delta R^{2}$ & .10 & & & .11 & & & .09 & & \\
\hline$R^{2}\left(\mathrm{f}^{2}\right)$ & $.18^{*}(.11)$ & & & $.19 *(.14)$ & & & $.18^{*}(.12)$ & & \\
\hline
\end{tabular}

LWIG = Laurens Well-being Inventory for Geronto-psychiatry; NPI = Neuropsychiatric Inventory; tension component contains irritability, agitation and anxiety, disinhibition component contains disinhibition, euphoria and aberrant motor behavior, depression component contains nighttime behavior, depression, apathy and appetite, psychosis component contains delusions and hallucinations; CMAI = Cohen Mansfield Agitation Index.

$*_{p}<.05, * * p<.01$.

Table 3. Standard multiple regression of behavioral problems on observed well-being scores.

\begin{tabular}{|c|c|c|c|c|c|c|}
\hline & \multicolumn{3}{|c|}{ LWOG psychological-negative } & \multicolumn{3}{|c|}{ LWOG social-positive } \\
\hline & & $B(S E)$ & $\beta$ & & $B(S E)$ & $\beta$ \\
\hline \multicolumn{7}{|l|}{ Block 1} \\
\hline Constant & & $2.39(.41)$ & & & $2.58(.30)$ & \\
\hline Sex & & $-.18(.15)$ & -.11 & & $.09(.11)$ & .07 \\
\hline Barthel score & & $.03(.01)$ & $.23^{*}$ & & $-.00(.01)$ & .01 \\
\hline GAF & & $.00(.01)$ & .02 & & $.01(.01)$ & .17 \\
\hline Level of education & & $.06(.04)$ & .13 & & $.00(.03)$ & .00 \\
\hline$R^{2}$ & $.08^{*}$ & & & .04 & & \\
\hline \multicolumn{7}{|l|}{ Block 2} \\
\hline Constant & & $2.91(.37)$ & & & $2.85(.35)$ & \\
\hline Sex & & $-.06(.11)$ & -.04 & & $.12(.11)$ & .10 \\
\hline Barthel score & & $.01(.01)$ & .08 & & $-.00(.01)$ & -.04 \\
\hline GAF & & $.01(.01)$ & .10 & & $.01(.01)$ & $.20 *$ \\
\hline Level of education & & $.06(.03)$ & .13 & & $-.01(.03)$ & -.02 \\
\hline Tension component & & $-.28(.07)$ & $-.33^{* * *}$ & & $-.16(.07)$ & $-.25^{*}$ \\
\hline Disinhibition component & & $.19(.09)$ & $.16^{*}$ & & $.20(.09)$ & $.23^{*}$ \\
\hline Depression component & & $-.37(.09)$ & $-.31 * * *$ & & $-.12(.09)$ & -.14 \\
\hline Psychosis component & & $-.13(.06)$ & $-.15^{*}$ & & $.04(.06)$ & .06 \\
\hline CMAI verbally aggressive & & $-.19(.04)$ & $-.39 * * *$ & & $-.01(.04)$ & -.03 \\
\hline CMAI physical not-aggressive & & $.07(.07)$ & .07 & & $-.04(.07)$ & -.05 \\
\hline CMAI physical aggressive & & $.20(.10)$ & $.16^{*}$ & & $-.06(.09)$ & -.07 \\
\hline$\Delta R^{2}$ & $.45^{* * *}$ & & & $.13^{*}$ & & \\
\hline$R^{2}\left(\mathrm{f}^{2}\right)$ & $.53^{* * *}(1.00)$ & & & $.17^{*}(.16)$ & & \\
\hline
\end{tabular}

LWOG = Laurens Well-being Observations for Gerontopsychiatry; NPI = Neuropsychiatric Inventory; tension component contains irritability, agitation and anxiety, disinhibition component contains disinhibition, euphoria and aberrant motor behavior, depression component contains nighttime behavior, depression, apathy and appetite, psychosis component contains delusions and hallucinations; CMAI = Cohen Mansfield Agitation Index.

$* p<.05, * * * p<.001$.

\section{Behavior and well-being}

\section{Self-rated well-being}

The relevant covariates were sex, ADL dependence, level of education and level of functioning. Forced entry analysis was used with the relevant covariates in the first block, and psychiatric or behavioral problems, measured with the CMAI and the NPI in the second block. For the results on the self-rated well-being subscales, see Table 2. For all three subscales the first model is significant, mainly due to sex (men have higher well-being scores than women) and for the psychological subscale also ADL dependence (more dependence is related to lower psychological well-being) is a significant predictor of the well-being score. The second model is significant in all three subscales with small to medium effect sizes, even though the change in $R^{2}$ is not. None of the covariates add significantly in the second model. For physical and social wellbeing only the NPI depression component has a significant negative relationship with well-being. For psychological wellbeing, there is a positive relationship with the NPI disinhibition component, and a negative relationship with the NPI tension component. None of the CMAI subscales was significantly related to well-being.

\section{Observed well-being}

For observed well-being the results of the hierarchical multiple regression are found in Table 3. The models were 
structured in the same way as the models for self-rated well-being. For the psychological-negative subscale of the LWOG a large proportion (45\%) of the variance is explained by psychiatric and behavioral problems. The effect size is large, cohen's $f^{2}=1.0$. The strongest contributors for this relationship are the NPI tension and depression components and the verbal aggressive subscale of the CMAI. However, also the NPI psychosis component was related to lower well-being, whereas the NPI disinhibition component and the CMAI physical aggression subscale were related to higher levels of observed well-being. The results differed for the social-positive subscale of the LWOG. Only $12 \%$ of the variance was explained by psychiatric and behavioral problems with a medium effect size. For this subscale there was a positive relationship with the NPI disinhibition component, and a negative relationship with the NPI tension component. The results are similar to the results on selfrated psychological well-being.

\section{Discussion}

This study aimed to examine how psychiatric and behavioral problems are related to well-being among gerontopsychiatric nursing home residents. Specifically, we aimed to investigate if the strength of this relationship is associated with the method of measurement, comparing the results from a self-rated well-being measure with the results of an observer-rated measure, conducted by the first-responsible nurse. We hypothesized a moderate relationship for caregiver-observed well-being and behavioral problems, and a weak relationship for self-rated well-being and behavioral problems.

Firstly, as there is ambiguity in the term nursing home, and the term may have a different meaning in different countries (Sanford et al., 2015), it is important to discuss the type of residence in the context of this study. A nursing home in The Netherlands is a high level care facility, where people can live in a homely environment, and where nearly all medical care can be provided within the nursing home. People generally stay here until their death. The gerontopsychiatric population lives in special units, or a specialized nursing home, and is not placed in wards with people with dementia or with purely somatic complaints. This approach differs between European countries and the USA. In the USA the gerontopsychiatric population is generally admitted to standard nursing home care, and lives in wards with people with dementia or somatic disorders (Fullerton et al., 2009; Grabowski, Aschbrenner, Rome, \& Bartels, 2010). A unique specialty in The Netherlands is the elderly care physician, a physician who is employed by the nursing home (Sanford et al., 2015)

Several differences were found between self-rated and observer-rated well-being and their relationship with problem behavior. Firstly, although all self-rated well-being subscales were associated with one or more behavioral problems even after controlling for other relevant resident characteristics, the relationship to behavioral problems was greater for observed well-being than for self-rated wellbeing. There were also some behaviors that were associated with lower observed well-being (i.e. the NPI psychosis component and CMAI verbal aggression), that were not related to lower self-rated well-being.
The NPI depression component was related to both lower self-rated physical and social well-being and to lower observed psychological-negative well-being. This is in line with a previous study on depression and well-being in the gerontopsychiatric population (Smalbrugge et al., 2006). The NPI tension component was related to lower self-rated psychological well-being and to lower scores on both of the observed well-being subscales. Since happiness is enhanced by prosocial and positive behavior (Sin \& Lyubomirsky, 2009; Warner \& Vroman, 2011), it is conceivable to assume that the opposite is also true, that negative behavior works as a reinforcement of somberness and low mood. This line of thought is supported by a small study among nursing home residents with dementia (Kristin Martin-Cook et al., 2005). Also, the negative relationship to items within the NPI tension component (i.e. agitation, irritability and anxiety) are in line with the outcomes of another study among long term care residents with dementia (Samus et al., 2005).

Interestingly, the NPI disinhibition component, was related to higher observed well-being and to a higher score on the psychological subscale from the LWIG. The NPI disinhibition component contains items on disinhibition, euphoria and aberrant motor behavior. When looking at correlations of the separate items with both the selfrated psychological well-being subscale and the observed well-being subscales, the strongest positive correlation was found for the euphoria item. It is also possible that abnormally elevated mood adds to well-being. The fact that both self-rated and observed well-being are positively related to this subscale, provides a strong indication that there is indeed a positive association between the behaviors in the NPI disinhibition component and well-being.

Another unexpected positive relation was found for the CMAI physical aggression subscale, which was related to higher observed psychological well-being on the LWOG. The expression of physical aggression may be caused by disinhibition, pointing toward the idea that disinhibited behavior is related to higher well-being, as was argued previously. It is also possible that the low mean score on the physical aggression scale slightly inflated the relation. However, $55.6 \%$ of the participants was rated with one or more of the physical aggressive behaviors at least once a week. More research on the relation between physical aggression, disinhibition and well-being in the gerontopsychiatric population is strongly recommended.

In general one could say based on these positive relations, that some problem behaviors that may be experienced as a problem for the environment of the resident, may not actually be a problem for the residents themselves. They might even result from, or lead to a higher level of well-being of the resident. In research on longterm care residents with dementia however, this relationship was not found. Both disinhibition and aberrant motor behavior were associated with lower quality of life scores, and euphoria was not significantly related to quality of life (Samus et al., 2005). The prevalence of euphoric behavior is found to be higher in the gerontopsychiatric population (29.4\%) than in the population with dementia. Samus et al. (2005) do not give prevalence rates of the NPI symptoms, but Zuidema, Koopmans, and Verhey (2007) studied a similar population, and found a $7 \%$ prevalence rate for 
euphoria. A small prevalence rate may explain the absence of a significant relationship in a population of residents with dementia.

On all subscales, men rated their well-being higher than women. This is in line with previous research (Pinquart \& Sörensen, 2001). After adding the behavioral subscales the relation between gender and well-being is no longer significant. It might be that this difference between men and women is mainly explained by differences in behavior such as the higher score of women on the NPI depression component, as depressive symptoms are strongly related with well-being (Smalbrugge et al., 2006). It might also be the case that men and women experience and value their own problem behavior differently, or that their problem behavior is caused by different factors. This would be an interesting topic for future research.

\section{Strengths and weaknesses}

This study is, to the best of our knowledge the first study on the relationship between psychiatric and behavioral problems and the level of well-being among gerontopsychiatric nursing home residents. It aims to add to the understanding of how behavior and well-being are related, which is a first step toward improving our interpretation and treatment of behavioral problems, and enhancing resident well-being. The use of well-being scales that are specifically designed for the gerontopsychiatric population is one of the key strengths of this study. Another significant strength is the inclusion of both self-rated and observerrated well-being measures. Well-being is a broad and highly subjective construct, and to provide a complete picture, multiple perspectives should be included in the measurement (Sloane et al., 2005). An important limitation in this study is its cross-sectional design, as it limits the possibility of drawing conclusions on the direction of the relations. Another limitation is the amount of missing values, mainly in the observed-well-being scales. Exclusion of the cases with missing values would have resulted in the loss of quite a large percentage of the participant numbers, and subsequently loss of power for the analyses. The best solution was to impute the missing values using expectation maximization (Gold \& Bentler, 2000), but any solution to a large number of missing values can provide possible bias in the results.

A participation-rate of only $56 \%$ is not very high, however in this population participation rates around $50 \%$ are common (Depla, De Graaf, \& Heeren, 2005; Smalbrugge et al., 2006). The reasons for not participating varied from physical health problems to simply not feeling like participating. It can be assumed that more highly functioning residents participated more frequently, and residents with lower well-being or with more behavioral problems may be underrepresented. This may limit the generalizability of the results.

Furthermore, the factor structure of the NPI-Q as used in this study should be discussed. Factor analysis has been performed often with data from a dementia population, resulting in different factor structures e.g. (Aalten et al., 2007; Chen et al., 2018; Zuidema, De Jonghe, Verhey, \& Koopmans, 2007b). In 2012, a review was done on the studies that performed FA on the NPI up to then (Canevelli et al., 2013), and found some recurring patterns in the factor structure. The psychosis factor as found in this study, was found in all studies included by Canevelli et al. Also the combination of disinhibition and euphoria, and the combination of irritability and agitation/aggression was often found. Compared to the findings in Canevelli's review, one slightly unusual finding in our current study was the fact that anxiety and depression were not in the same factor. In conclusion the factor structure of the NPI as found in this study did not seem to differ greatly from findings in the dementia population

\section{Directions for future research and care practice}

As this is the first study on the relationship between psychiatric and behavioral problems and well-being in the gerontopsychiatric population, more research is recommended to determine if the research findings of an association of both self-rated and observer rated well-being with several behavioral problems can be verified. In order to study the direction of the relationship, experimental or longitudinal research on this topic would be strongly recommended. As mentioned previously, the relation between gender, selfrated well-being and behavioral problems might also be an interesting topic for future research. In longitudinal research, differences in the causes of behavioral problems and differences in the effects of these problems on levels of well-being might be studied among men and women. More insight into the differences in well-being and behavior between men and women could provide a direction for the development of treatment and care in daily care practice. Finally, future research might focus on some relevant characteristics of the observers, such as burden and feelings of depression, that could potentially influence their assessment of behavioral problems and of well-being.

Based on this study, some recommendations can be made for care practice. If the aims of the care institution are to strive for high well-being among the gerontopsychiatric residents, treatment should focus on depressive and apathetic behaviors, and also the more severe manifestations of irritability, anxiety and agitation. Also, improving the sense of well-being among the gerontopsychiatric population could lead to a decrease in irritable and agitated behavior, which in turn could prevent reductions in health status and job satisfaction of care employees (Evers et al., 2001; Testad et al., 2009). Finally, in this study we see several differences in the rating of well-being by residents themselves compared to the ratings by their primary responsible formal caregiver. A difference that has also been found in this population by Van den Brink et al. (2018) concerning unmet needs. It is important for (formal) caregivers to be aware of these differences, and to remain attentive to the perceptions of the residents themselves when it comes to well-being and its related factors.

\section{Conclusions}

Contrary to findings in long term care residents with dementia (Vogel et al., 2006; Yap et al., 2008; Zimmerman et al., 2005) but in accordance with our hypotheses, we found a relationship between self-rated well-being and several behavioral problems. Consistent with studies in 
participants with dementia, the relationship between wellbeing and behavioral problems was strongest when well-being was measured via observation measures. For irritability and affective problem behaviors the relation with well-being was the most evident, a finding that gives direction for care and treatment in daily care practice. More research on well-being and behavioral problems in the gerontopsychiatric population is needed to further explore this relation and strengthen conclusions on this topic.

Raw data were generated at several nursing homes. Derived data supporting the findings of this study are available from the corresponding author (EvdW) on request.

\section{Acknowledgements}

The authors thank the formal caregivers and participants in the nursing homes who consented to participate and invested their time in this study, Ann Richardson for checking the English text and the students who assisted with the interviews.

\section{Disclosure statement}

The authors report no conflict of interest.

\section{ORCID}

Elja van der Wolf (D) http://orcid.org/0000-0001-6636-3697 Lilian Lechner (iD http://orcid.org/0000-0002-5160-7086

\section{References}

Aalten, P., Verhey, F. R. J., Boziki, M., Bullock, R., Byrne, E. J., Camus, V., ... Robert, P. H. (2007). Neuropsychiatric syndromes in dementia. Dementia and Geriatric Cognitive Disorders, 24(6), 457-463. doi:10. 1159/000110738

Abraha, I., Rimland, J. M., Trotta, F. M., Dell'Aquila, G., Cruz-Jentoft, A., Petrovic, M., ... Cherubini, A. (2017). Systematic review of systematic reviews of non-pharmacological interventions to treat behavioural disturbances in older patients with dementia. The SENATOR-OnTop series. BMJ Open, 7(3), e012759. doi:10.1136/ bmjopen-2016-012759

Ballard, C., O'Brien, J., James, I., Mynt, P., Lana, M., Potkins, D., ... Fossey, J. (2001). Quality of life for people with dementia living in residential and nursing home care: The impact of performance on activities of daily living, behavioral and psychological symptoms, language skills, and psychotropic drugs. International Psychogeriatrics, 13(1), 93-106. doi:10.1017/S1041610201007499

Canevelli, M., Adali, N., Voisin, T., Soto, M. E., Bruno, G., Cesari, M., \& Vellas, B. (2013). Behavioral and psychological subsyndromes in Alzheimer's disease using the neuropsychiatric inventory. International Journal of Geriatric Psychiatry, 28(8), 795-803.

Cantril, H. (1965). Pattern of human concerns. New Brunswick: Rutgers University Press

Chen, S., Lin, K., Wang, H., Yamakawa, M., Makimoto, K., \& Liao, X (2018). Reliability and structural validity of the Chinese version of the neuropsychiatric inventory, nursing home version. Psychogeriatrics, 18(2), 113-122. doi:10.1111/psyg.12292

Chiu, Y., Bero, L., Hessol, N. A., Lexchin, J., \& Harrington, C. (2015). A literature review of clinical outcomes associated with antipsychotic medication use in North American nursing home residents. Health Policy, 119(6), 802-813. doi:10.1016/j.healthpol.2015.02.014

Clare, L. (2002). We'll fight it as long as we can: Coping with the onset of Alzheimer's disease. Aging \& Mental Health, 6(2), 139-148. doi:10. 1080/13607860220126826

Cohen, J. (1977). Statistical power analysis for the behavioral sciences (Rev ed.). Hillsdale, NJ: Lawrence Erlbaum Associates, Inc.

Cohen-Mansfield, J., \& Libin, A. (2004). Assessment of agitation in elderly patients with dementia: Correlations between informant rating and direct observation. International Journal of Geriatric Psychiatry, 19(9), 881-891. doi:10.1002/gps.1171

Cohen-Mansfield, J., Marx, M. S., \& Rosenthal, A. S. (1989). A description of agitation in a nursing home. Journal of Gerontology, 44(3), M77-M84. doi:10.1093/geronj/44.3.m77

Collet, J., De Vugt, M. E., Verhey, F. R., Engelen, N. J., \& Schols, J. M. (2016). Characteristics of double care demanding patients in a mental health care setting and a nursing home setting: Results from the SpeCIMeN study. Aging and Mental Health, 22(1), 33-39.

Cummings, J. L., Mega, M., Gray, K., Rosenberg-Thompson, S., Carusi, D. A., \& Gornbein, J. (1994). The Neuropsychiatric Inventory comprehensive assessment of psychopathology in dementia. Neurology, 44(12), 2308-2308. doi:10.1212/WNL.44.12.2308

De Jonghe, J., Kat, M. G., Kalisvaart, C., \& Boelaarts, L. (2003) Neuropsychiatric inventory questionnaire (NPI-Q): A validity study of the Dutch form. Tijdschrift Voor Gerontologie en Geriatrie, 34(2), 74-77.

Depla, M., De Graaf, R., \& Heeren, T. (2005). Does supported living in residential homes improve the quality of life and mental stability of older adults with chronic mental disorder? American Journal of Geriatric Psychiatry, 13(2), 124-133. doi:10.1176/appi.ajgp.13.2.124

Endicott, J., Spitzer, R. L., Fleiss, J. L., \& Cohen, J. (1976). The global assessment scale: A procedure for measuring overall severity of psychiatric disturbance. Archives of General Psychiatry, 33(6), 766-771. doi:10.1001/archpsyc.1976.01770060086012

Ettema, T. P., Dröes, R. M., De Lange, J., Mellenbergh, G. J., \& Ribbe, M. W. (2007). QUALIDEM: Development and evaluation of a dementia specific quality of life instrument--validation. International Journal of Geriatric Psychiatry, 22(5), 424-430. doi:10.1002/gps.1692

Evers, W., Tomic, W., \& Brouwers, A. (2001). Effects of aggressive behavior and perceived self-efficacy on burnout among staff of homes for the elderly. Issues in Mental Health Nursing, 22(4), 439-454.

Field, A. (2009). Discovering statistics using SPSS. London: Sage Publications.

Fullerton, C. A., McGuire, T. G., Feng, Z., Mor, V., \& Grabowski, D. C. (2009). Trends in mental health admissions to nursing homes, 1999-2005. Psychiatric Services, 60(7), 965.

Gold, M. S., \& Bentler, P. M. (2000). Treatments of missing data: A Monte Carlo comparison of $\mathrm{RBHDI}$, iterative stochastic regression imputation, and expectation-maximization. Structural Equation Modeling: A Multidisciplinary Journal, 7(3), 319-355. doi:10.1207/ S15328007SEM0703_1

Grabowski, D., Aschbrenner, K., Rome, V., \& Bartels, S. (2010). Review: Quality of mental health care for nursing home residents: A literature review. Medical Care Research and Review, 67(6), 627-656. doi: $10.1177 / 1077558710362538$

Hamers, J. (2011). De intramurale ouderenzorg: nieuwe leiders, nieuwe kennis, nieuwe kansen [Intramural care for elderly: new leaders, new knowledge, new chances]. Retrieved from https://www.raadrvs.nl/ binaries/raadrvs/documenten/publicaties/2012/06/08/achtergrondstudie-toekomstintramurale-ouderenzorg/Achtergrondstudie Toekomstintramurale_Ouderenzorg.pdf

Herrmann, N., Lanctôt, K. L., Sambrook, R., Lesnikova, N., Hébert, R., McCracken, P., ... Nguyen, E. (2006). The contribution of neuropsychiatric symptoms to the cost of dementia care. International Journal of Geriatric Psychiatry, 21(10), 972-976. doi:10.1002/gps.1594

Kaufer, D. I., Cummings, J. L., Ketchel, P., Smith, V., MacMillan, A., Shelley, T., ... DeKosky, S. T. (2000). Validation of the NPI-Q, a brief clinical form of the neuropsychiatric inventory. The Journal of Neuropsychiatry and Clinical Neurosciences, 12(2), 233-239. doi:10. 1176/jnp.12.2.233

Kristin Martin-Cook, K., Hynan, L. S., Rice-Koch, K., Svetlik, D. A., \& Weiner, M. F. (2005). Responsiveness of the quality of life in latestage dementia scale to psychotropic drug treatment in late-stage dementia. Dementia and Geriatric Cognitive Disorders, 19(2-3), 82-85.

Logsdon, R. G., Gibbons, L. E., McCurry, S. M., \& Teri, L. (2002). Assessing quality of life in older adults with cognitive impairment. Psychosomatic Medicine, 64(3), 510-519. doi:10.1097/00006842200205000-00016

Mahoney, F. I., \& Barthel, D. W. (1965). Functional evaluation: The Barthel index: A simple index of independence useful in scoring improvement in the rehabilitation of the chronically ill. Maryland State Medical Journal, 14, 56-61. 
Neubauer, S., Holle, R., Menn, P., Grossfeld-Schmitz, M., \& Graesel, E. (2008). Measurement of informal care time in a study of patients with dementia. International Psychogeriatrics, 20(06), 1160-1176. doi: $10.1017 /$ S1041610208007564

Pinquart, M., \& Sörensen, S. (2001). Gender differences in self-concept and psychological well-being in old age: A meta-analysis. The Journals of Gerontology Series B: Psychological Sciences and Social Sciences, 56(4), P195-P213. doi:10.1093/geronb/56.4.P195

Ryan, R. M., \& Deci, E. L. (2001). On happiness and human potentials: A review of research on hedonic and eudaimonic well-being Annual Review of Psychology, 52(1), 141-166. doi:10.1146/annurev. psych.52.1.141

Sainsbury, A., Seebass, G., Bansal, A., \& Young, J. B. (2005). Reliability of the Barthel index when used with older people. Age and Ageing, 34(3), 228-232. doi:10.1093/ageing/afi063

Samus, Q. M., Rosenblatt, A., Steele, C., Baker, A., Harper, M., Brandt, J., ... Lyketsos, C. G. (2005). The association of neuropsychiatric symptoms and environment with quality of life in assisted living residents with dementia. The Gerontologist, 45(suppl_1), 19-26. doi:10. 1093/geront/45.suppl_1.19

Sanford, A. M., Orrell, M., Tolson, D., Abbatecola, A. M., Arai, H., Bauer, J. M., ... Vellas, B. (2015). An international definition for "nursing home". Journal of the American Medical Directors Association, 16(3), 181-184. doi:10.1016/j.jamda.2014.12.013

Sin, N. L., \& Lyubomirsky, S. (2009). Enhancing well-being and alleviating depressive symptoms with positive psychology interventions: A practice-friendly meta-analysis. Journal of Clinical Psychology, 65(5), 467-487. doi:10.1002/jclp.20593

Sloane, P. D., Zimmerman, S., Williams, C. S., Reed, P. S., Gill, K. S., \& Preisser, J. S. (2005). Evaluating the quality of life of long-term care residents with dementia. The Gerontologist, 45(suppl_1), 37-49. doi: 10.1093/geront/45.suppl_1.37

Smalbrugge, M., Pot, A. M., Jongenelis, L., Gundy, C. M., Beekman, A. T., \& Eefsting, J. A. (2006). The impact of depression and anxiety on well being, disability and use of health care services in nursing home patients. International Journal of Geriatric Psychiatry, 21(4), 325-332. doi:10.1002/gps.1466

Soper, D. S. (2019). Effect size calculator for hierarchical multiple regression. Retrieved from http://www.danielsoper.com/statcalc

Stuurgroep Gerontopsychiatrie. (2012). Zorgprogramma voor mensen met gerontopsychiatrische problematiek in het verpleeghuis, Gouda

Tabachnick, B. G., \& Fidell, L. S. (2014). Using multivariate statistics (6th ed.) Harlow: Pearson Education

Tatsumi, H., Nakaaki, S., Torii, K., Shinagawa, Y., Watanabe, N., Murata, Y., ... Furukawa, T. A. (2009). Neuropsychiatric symptoms predict change in quality of life of Alzheimer disease patients: A two-year follow-up study. Psychiatry and Clinical Neurosciences, 63(3), 374-384. doi:10.1111/j.1440-1819.2009.01955.x

Testad, I., Mikkelsen, A., Ballard, C., \& Aarsland, D. (2009). Health and well-being in care staff and their relations to organizational and psychosocial factors, care staff and resident factors in nursing homes. International Journal of Geriatric Psychiatry, 25(8), 789-797. doi:10.1002/gps.2419

Van den Brink, A. M., Gerritsen, D. L., de Valk, M. M., Mulder, A. T., Voshaar, R. C. O., \& Koopmans, R. T. (2018). What do nursing home residents with mental-physical multimorbidity need and who actually knows this? A cross-sectional cohort study. International Journal of Nursing Studies, 81, 89-97. doi:10.1016/j.jjnurstu.2018.02.008

Van den Brink, A. M., Gerritsen, D. L., De Valk, M. M., Voshaar, R. C. O. \& Koopmans, R. T. (2017). Characteristics and health conditions of a group of nursing home patients with mental-physical multimorbidity-The MAPPING study. International Psychogeriatrics 29(6), 1037-1047. doi:10.1017/S1041610217000230

Van den Brink, A. M., Gerritsen, D. L., Voshaar, R. C., \& Koopmans, R. T. (2013). Residents with mental-physical multimorbidity living in long-term care facilities: Prevalence and characteristics. A systematic review. International Psychogeriatrics, 25(4), 531-548. doi:10.1017/ S1041610212002025

Van der Wolf, E., Van Hooren, S. A. H., Waterink, W., \& Lechner, L. (2017). Well-being in elderly long-term care residents with chronic mental disorder: A systematic review. Aging and Mental Health, 23(3), 287-296.

Van der Wolf, E., Van Hooren, S. A. H., Waterink, W., \& Lechner, L. (2018). Measurement of well-being in gerontopsychiatric nursing home residents: Development of the Laurens Well-Being Inventory for Gerontopsychiatry. Journal of Geriatric Psychiatry and Neurology, 31(3), 136-148. doi:10.1177/0891988718781031

Ven-Vakhteeva, J. V. D., Bor, H., Wetzels, R. B., Koopmans, R. T. C. M., \& Zuidema, S. U. (2013). The impact of antipsychotics and neuropsychiatric symptoms on the quality of life of people with dementia living in nursing homes. International Journal of Geriatric Psychiatry, 28(5), 530-538. doi:10.1002/gps.3858

Vogel, A., Mortensen, E. L., Hasselbalch, S. G., Andersen, B. B., \& Waldemar, G. (2006). Patient versus informant reported quality of life in the earliest phases of Alzheimer's disease. International Journal of Geriatric Psychiatry, 21(12), 1132-1138. doi:10.1002/gps. 1619

Warner, R. M., \& Vroman, K. G. (2011). Happiness inducing behaviors in everyday life: An empirical assessment of "the how of happiness". Journal of Happiness Studies, 12(6), 1063-1082. doi:10.1007/s10902010-9245-3

Winzelberg, G. S., Williams, C. S., Preisser, J. S., Zimmerman, S., \& Sloane, P. D. (2005). Factors associated with nursing assistant quality-of-life ratings for residents with dementia in long-term care facilities. The Gerontologist, 45(suppl_1), 106-114. doi:10.1093/geront/45.suppl_1.106

Yap, P. L. K., Goh, J. Y. N., Henderson, L. M., Han, P. M., Ong, K. S., Kwek, S. S. L., ... Loh, D. P. K. (2008). How do Chinese patients with dementia rate their own quality of life? International Psychogeriatrics, 20(3), 482-493. doi:10.1017/S1041610207006096

Zimmerman, S., Sloane, P. D., Williams, C. S., Reed, P. S., Preisser, J. S. Eckert, J. K., ... Dobbs, D. (2005). Dementia care and quality of life in assisted living and nursing homes. The Gerontologist, 45(suppl_1) 133-146. doi:10.1093/geront/45.suppl_1.133

Zuidema, S. U., De Jonghe, J. F., Verhey, F. R., \& Koopmans, R. T. (2007a). Agitation in Dutch institutionalized patients with dementia: Factor analysis of the Dutch version of the Cohen-Mansfield agitation inventory. Dementia and Geriatric Cognitive Disorders, 23(1) 35-41. doi:10.1159/000096681

Zuidema, S. U., De Jonghe, J. F., Verhey, F. R., \& Koopmans, R. T. (2007b). Neuropsychiatric symptoms in nursing home patients: Factor structure invariance of the Dutch nursing home version of the neuropsychiatric inventory in different stages of dementia. Dementia and Geriatric Cognitive Disorders, 24(3), 169-176. doi:10. $1159 / 000105603$

Zuidema, S. U., Koopmans, R., \& Verhey, F. (2007). Prevalence and predictors of neuropsychiatric symptoms in cognitively impaired nursing home patients. Journal of Geriatric Psychiatry and Neurology, 20(1), 41-49. doi:10.1177/0891988706292762 